\title{
Bark Company Owner Dies After Being Crushed By Ecology Block Wall
}

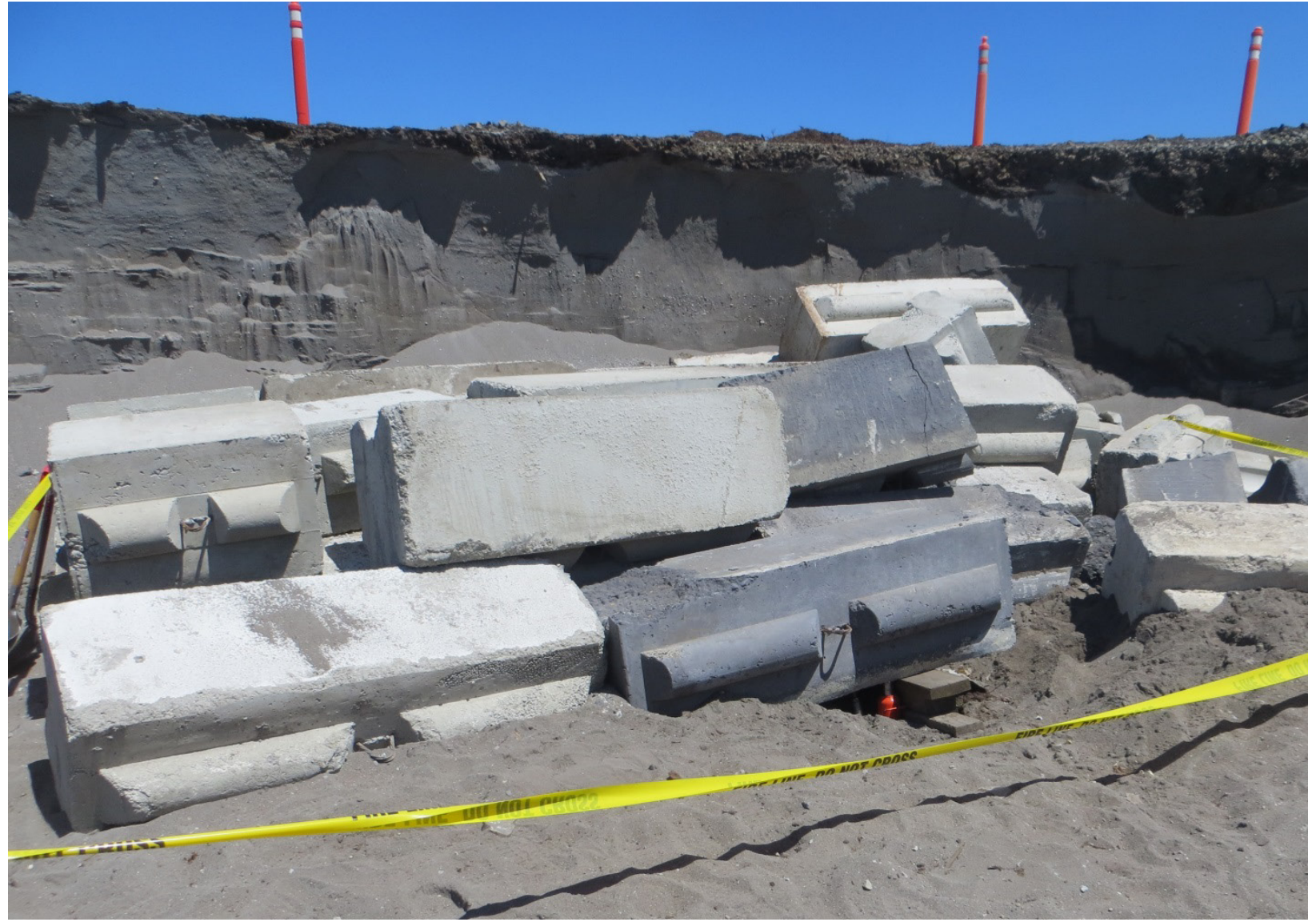

Investigation: \# 15WA02901

Release Date: December 19, 2016

SHARP Report: 52-39-2016

O) 


\section{Table of Contents}

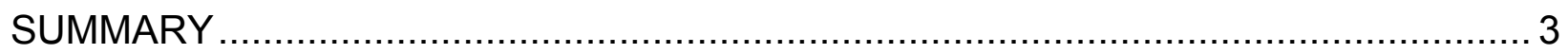

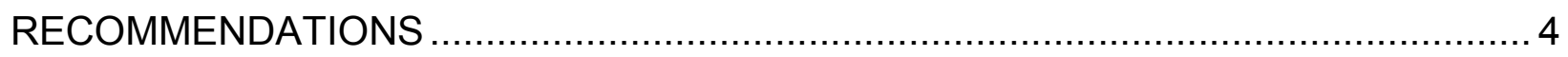

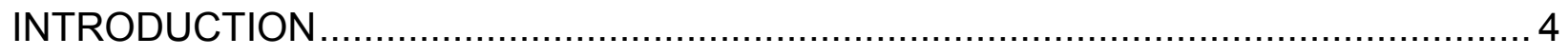

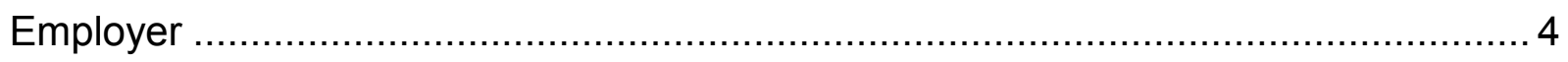

Employer Safety Training Program ............................................................... 4

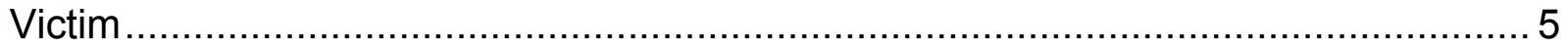

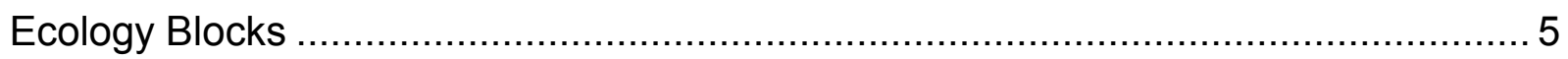

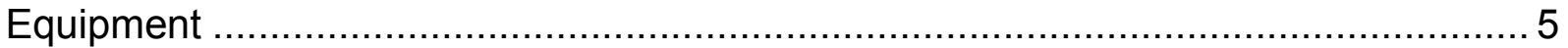

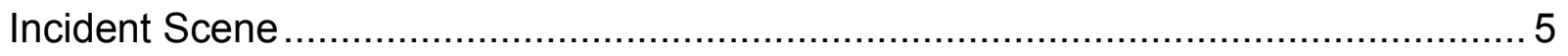

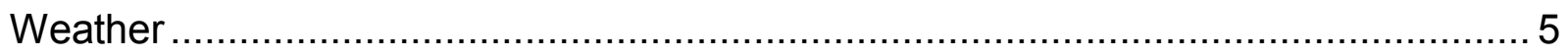

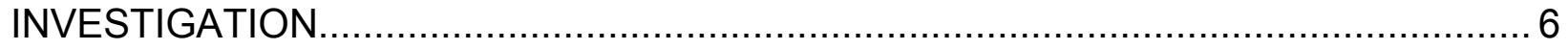

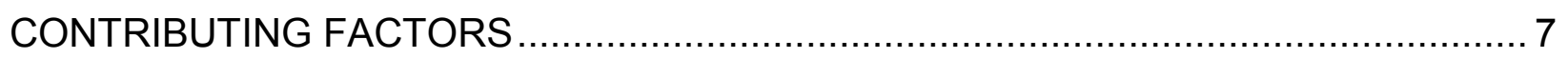

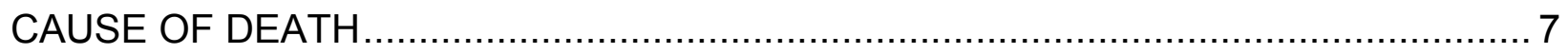

POST-INCIDENT CORRECTIVE ACTIONS TAKEN BY EMPLOYER .......................... 8

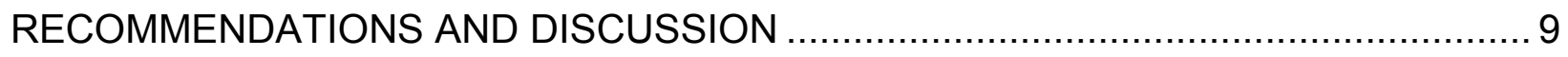

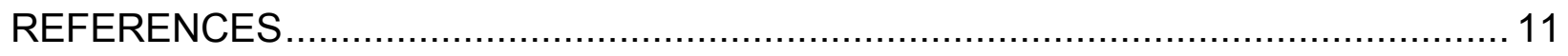

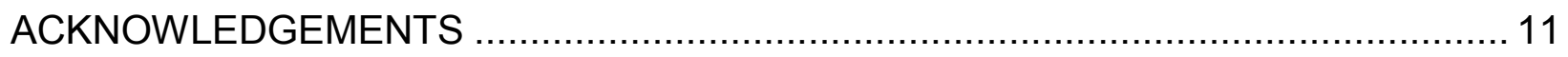

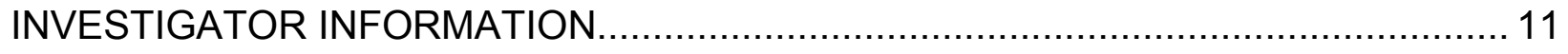

WASHINGTON STATE FACE PROGRAM INFORMATION ...................................... 11

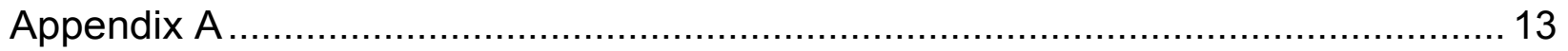




\section{SUMMARY}

In July of 2016, the 70-year-old owner of a bark and wood wholesale and retail company died from surgical complications resulting from injuries he sustained when a wall being constructed from concrete "ecology blocks" collapsed, and a 3600lb. block fell onto him, crushing his legs.

On the day of the incident, the victim and three other employees planned to complete construction of an "L"-shaped material containment bunker on a base of dry, loose sand. They were assembling the bunker using dry-stacked concrete ecology blocks that interlocked on the top and bottom with a tongue and groove system. The blocks were lifted and moved into place using a chain attached to the bucket of an excavator that was looped through a rebar picking-eye on the top of the block. While the employer frequently constructed and used ecology block retaining walls for various purposes, this was to be the first of this height built on sand.

The first section of the bunker had been completed the previous day. It consisted of two adjacent walls, each approximately 21 feet long and 10 feet (5 blocks) high. When completed, employees reported that the walls appeared to be sitting level on the sand. The second section of the bunker was to consist of an 18-foot wall, perpendicular to the first wall, with rows of 6 -foot-long ecology blocks horizontally stacked 5 blocks high.

On the morning of the incident, as the excavator operator was lowering the first block of the second bunker section into place, the victim stood near and used a shovel to guide the block's alignment. The two other employees were working near the victim. As the block was set onto the sand against the base of the inside wall of the first bunker section, both original walls began to destabilize and collapse. The victim and the two employees ran to avoid the falling blocks. At some point, the victim hesitated and turned back to look at the wall and was struck by a falling block, crushing his right leg and pinning him to the ground.

First responders arrived within minutes and transported the victim by helicopter to a local hospital where he remained in critical condition for nearly a month, after which he died due to complications following multiple surgeries. 


\section{RECOMMENDATIONS}

To prevent similar incidents, Washington State Fatality Assessment and Control Evaluation (WA FACE) recommends that employers engaged in similar work:

- Plan and design bulk material storage areas for safety and stability. Make sure all walls, whether temporary or permanent, are built on a stable foundation able to support the weight of the structure.

- Develop, implement, and enforce a comprehensive written safety program that is tailored to ecology block wall construction. Create Standard Operating Procedures that address hazards in both construction of and working near ecology block walls. Ensure that all employees are trained in and follow the procedures.

- Conduct a thorough job hazard analysis (JHA) before construction begins on any project involving stacked ecology blocks.

- Encourage employees to recognize and report safety concerns, and train workers on the protocol for reporting hazards. Ensure that all safety concerns are effectively addressed before employees are further exposed to the hazard.

\section{INTRODUCTION}

In July of 2015, the Washington State Division of Occupational Safety and Health (DOSH) notified the Washington State Fatality Assessment and Control Evaluation (FACE) program of the death of a 70-year-old bark and wood products company owner.

WA FACE investigators interviewed company management officials, including both the current and former Environmental Health and Safety coordinators for the company.

\section{Employer}

The company is a bark and wood products wholesaler and retailer. It was purchased by the victim in 1994, originally at a different location. Around 2000, the business moved to its current location. In subsequent years, the company acquired adjacent parcels, growing the business to over 84 acres. The configuration and location of material stored at the site changes frequently due to business needs. At the time of the incident, the company employed approximately 130 workers.

\section{Employer Safety Training Program}

At the time of the incident, the company had a written safety training program, but it did not specifically cover hazards posed by ecology block walls or their construction. Training on the construction of ecology block walls occurred on the job from employees 
who had past experience and was limited to those with direct involvement in wall construction.

The company employed a dedicated Environmental Health and Safety Coordinator at the time of the incident, as well as a safety committee that met on a monthly basis. The Safety Coordinator had not been informed of the plan to build the wall.

\section{Victim}

The victim was the company owner. He had a background in agriculture and was a certified public accountant. He purchased the bark business in 1994. He remained active in all aspects of the business, and worked onsite regularly, up until the time of the incident. He had built numerous ecology block walls in the past.

\section{Ecology Blocks}

Ecology blocks are stackable concrete blocks designed with an interlocking tongue and groove system on the top and bottom, and sometimes sides, for stability (photo 1). Other names include Eco-blocks, bin blocks, and bunker blocks. They are manufactured from unused concrete left over from other construction processes. Common ecology

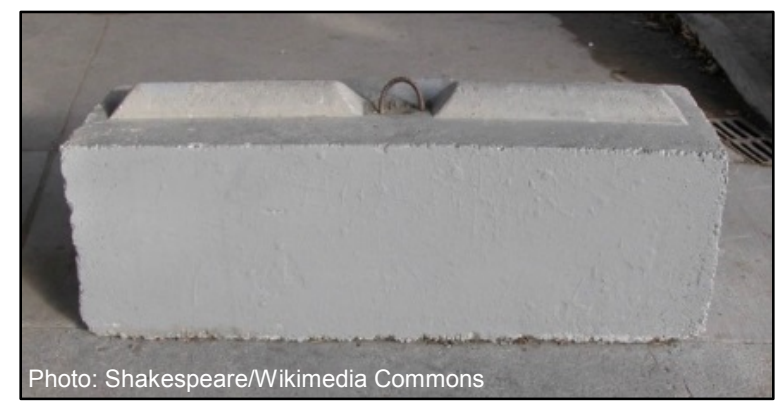

Photo 1: Concrete ecology block block dimensions are 2' $\times 2$ ' $\times$ 3', 2' $\times 2$ ' x 4', and 2' x 2' x 6'. They typically weigh between 1800 and 4000 pounds. They are usually equipped with a rebar loop, or picking eye, on the top of the block for loading, unloading, and placement. Ecology blocks are marketed for use in retaining walls, storage of bulk materials, and other applications. Their modular nature makes them convenient to use when permanent structures would not meet the needs of the user.

\section{Equipment}

The ecology blocks were lifted and set into place with an excavator, using a chain attached to the excavator bucket and run through the picking eye of the ecology block.

\section{Incident Scene}

The incident occurred in an area of the property that contained sand dredged from the nearby river. The site where the wall was being constructed had been previously dug out of the large sand pile, and was about one foot away from the base of an approximately ten-foot-high sand wall that sloped away from the wall. The site was near the location of the hopper used for a soil screening process, and would be used to store material used in that process. There was no asphalt or concrete surface beneath the sand.

\section{Weather}

The weather on the day of the incident was sunny and warm, with no precipitation. The weather had been similar for the two preceding weeks. ${ }^{1}$ 


\section{INVESTIGATION}

Around 9:00 a.m. on the morning of the incident, the victim and three other employees arrived at the site to complete construction of a material containment bunker. The victim, who was the owner of the company, had developed the design for the bunker. His plan was to create an "L-shaped" structure, approximately 10 feet high built, from dry-stacked concrete ecology blocks (figure 1). The blocks being used were 3'x2'x2' and 6'x2'x2', weighing approximately 1800 and 3600 pounds respectively, and interlocked on the top and bottom with a tongue and groove system.

Figure 1. Two views of planned bunker design
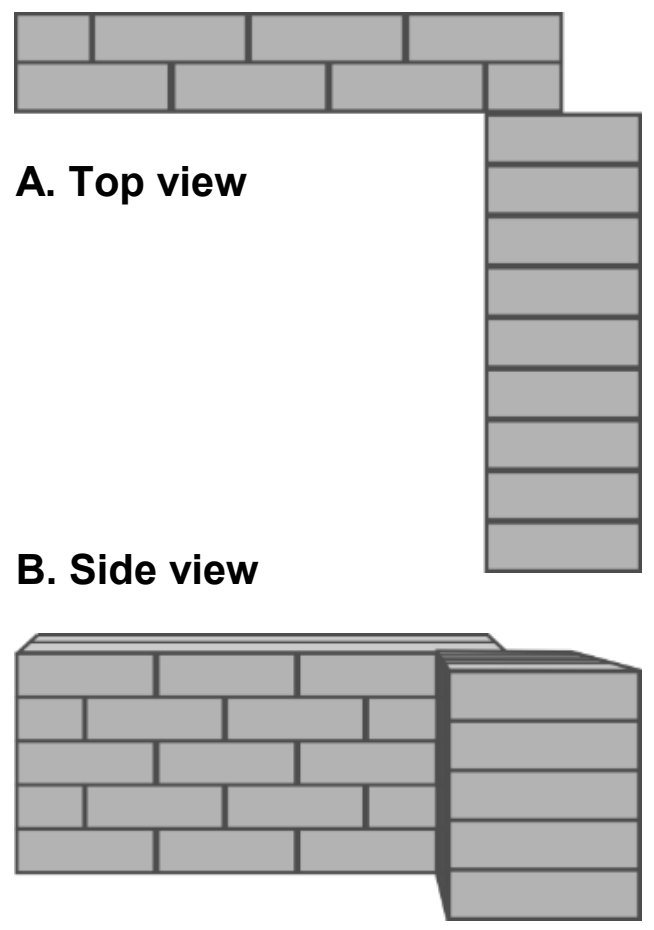

The bunker was going to be located in the corner of a sandy area on site to house and store a bark product. Much of the sand in the area had already been used as part of this process. The victim felt that a bunker in this location would keep the material as near as possible to the position of a hopper used in the production process, as well as separated from another finished product and away from a sand wall bordering the area.

The company regularly built and used ecology block walls and structures of similar design and height throughout the jobsite, in both the wholesale and retail areas, for a variety of purposes, but this was to be the first of this height built on sand. The victim and the three other employees had experience building ecology block walls.

During the investigation, it was reported that some of the other employees had voiced concerns about the safety of building a wall of

this height on a sand base, but that the victim had indicated that he believed that the second wall would add stability for the structure, and continued with the planned construction. According to management officials, there was no rush to complete the job.

They had completed construction of the first section of the bunker the previous day. It consisted of two adjacent walls, each 21 feet long and five blocks high. Each wall was stacked in an alternating, or offset, fashion, so that the ends of the blocks in one row would meet in the center of the blocks of the next row.

That morning, the victim and crew planned to build the second section of the bunker by building an 18-foot wall perpendicular to the first wall. This wall would consist of a row of ecology blocks stacked five blocks high and nine blocks deep in the same horizontal plane as the first walls. One of the workers used the excavator to lift the first ecology block and move it into place. The excavator was in the same position that it had been in the previous day, facing the completed section, and had not been driven at the site that morning. As the excavator operator lowered the first block to the ground, the victim 
stood near and used a hand shovel to push on the edge of the block to line it up correctly with the first wall. The other two workers stood near the first wall sections.

As the block was set down on the sand against the base of the first section (figure 2), the walls became unstable and began to collapse. The victim and workers ran to try to avoid the falling blocks. Witnesses reported that, at some point, as he was running, the victim paused for a moment to look behind him, and then began

Figure 2. Placement of block (in red) immediately preceding wall collapse

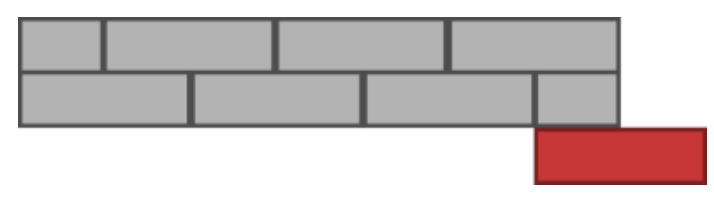
running again. Before he was able to get clear, one of the blocks that had been on the top of the wall struck him from behind and landed on him, crushing his right leg and pinning him against the ground. Both of the other workers were able to escape uninjured.

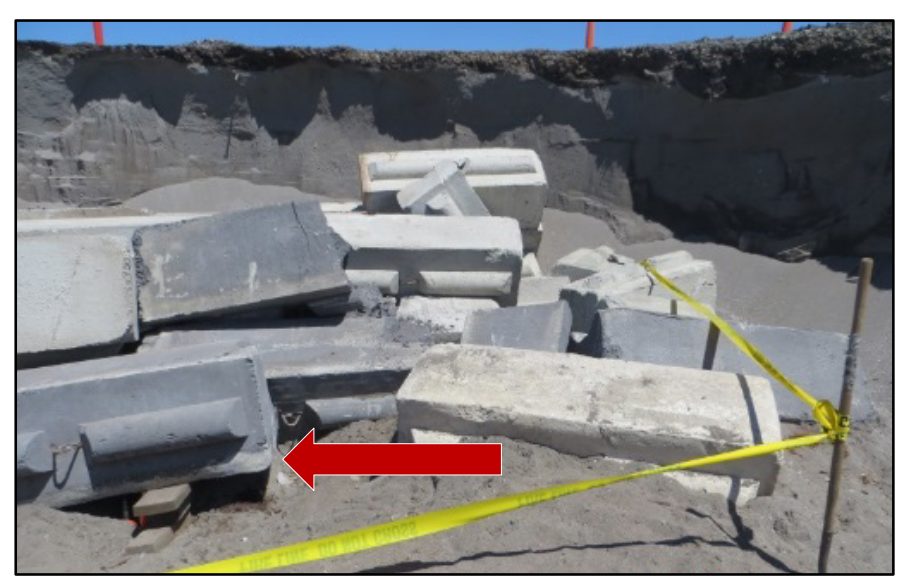

Photo 2. Collapsed ecology block wall. Arrow indicates block that struck victim
First responders arrived on the scene within minutes and were able to free the victim. He was transported by helicopter to a regional trauma facility. He underwent numerous surgeries, including the amputation of his right leg, and remained in intensive care until he passed away nearly one month later due to complications from the injury.

\section{CONTRIBUTING FACTORS}

- Attempting to build a ten-foot-high ecology block wall on an unstable sand surface

- Lack of discussion of possible safety risks or hazards before beginning work

- Unwillingness to challenge the company owner about safety concerns

\section{CAUSE OF DEATH}

The death certificate listed the immediate cause of death as Medical sequelae of crush injuries of the pelvis and lower extremities. 


\section{POST-INCIDENT CORRECTIVE ACTIONS TAKEN BY EMPLOYER}

After the incident, the employer developed a detailed safety program and standard operating procedures that address hazards in both construction of and working near ecology block walls. The safety training component of the program uses a three-tiered approach based on how much exposure an employee will have to ecology block hazards depending on their work duties. Employees are categorized as either "Certified," "Authorized," or "Affected." All employees are considered Affected workers and receive training regarding the hazards associated with working around ecology block walls as a component of new-hire training. Authorized employees receive more detailed training how to safely construct ecology block walls and are permitted to work on projects building or re-building walls. The training includes how to recognize hazards and the steps that employees should take to report concerns.

Certified employees receive the highest level of safety training. The construction of any new ecology block wall over two blocks high on the premises must go through a written planning and permitting process (Appendix A), which must be approved by two Certified employees. Two Certified employees must also perform a post-construction inspection of each new wall.

Safety "tail-gate" meetings are now mandatory before construction of a new wall begins, and before the start of each shift for walls requiring a permit.

The company's program also includes standard procedures for increasing the stability of walls when necessary, including doubling walls and binding blocks together

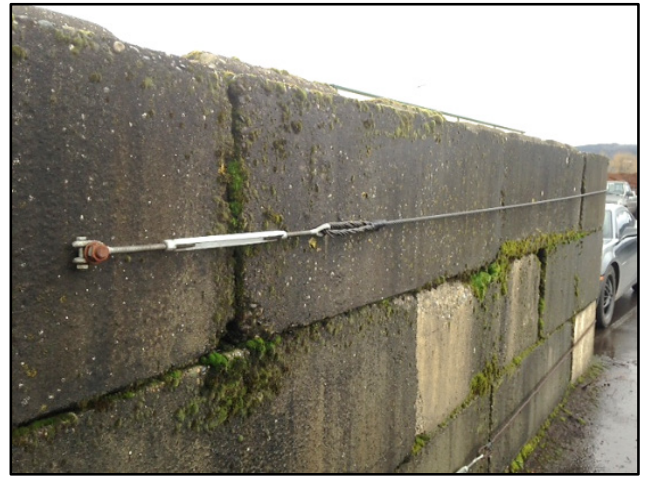

Photo 5. Steel cable bolted into side of ecology block wall

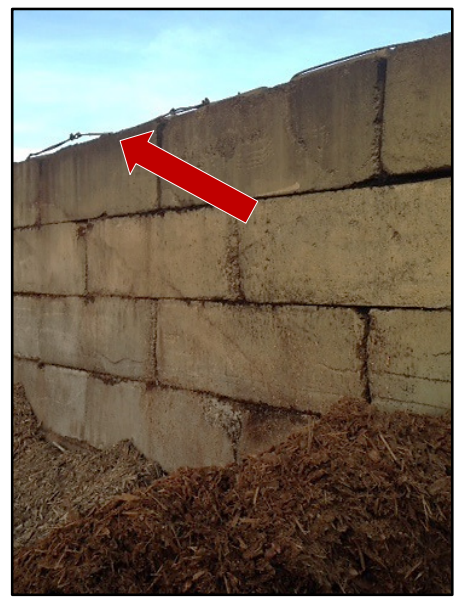

Photo 3. Steel cable threaded through ecology block picking eyes at top of wall

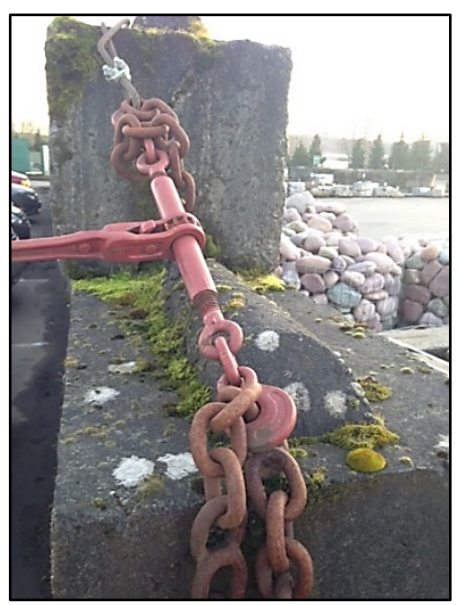

Photo 4. Ratchet mechanism for tightening wall cable using steel cabling anchored or bolted to the blocks (photos 3-5). Cabling was used frequently before the incident, as well.

In addition, every six months, a safety audit of all existing ecology block walls is performed by two Certified employees to check for damage, material leakage, strained cables, or structural instability. If necessary, walls are disassembled and rebuilt. 


\section{RECOMMENDATIONS AND DISCUSSION}

Recommendation 1: Plan and design bulk material storage areas for safety and stability. Make sure all walls, whether temporary or permanent, are built on a stable foundation able to support the weight of the structure.

Discussion: In this incident, a loose, dry sand based proved too unstable to support the weight of the walls. If dry-stacked ecology blocks or similar materials are to be used to create bulk material storage areas, structures must be built on firm footing. Develop siting criteria for ecology block wall construction to ensure that structures are only built on foundations that can safely support the weight of the walls. The evaluation should take into account details such as soil type, possibility of compaction, and whether there will be adequate water drainage. A registered professional engineer may be able to provide guidance on development of these criteria and foundation requirements for specific walls.

Recommendation 2: Develop, implement, and enforce a comprehensive written safety program that is tailored to ecology block wall construction. Create Standard Operating Procedures that address hazards in both construction of and working near ecology block walls. Ensure that all employees are trained in and follow the procedures.

Discussion: While the employer in this incident had a written safety program, hazards regarding ecology blocks were not specifically addressed. Interviews with management revealed that there was an awareness that working around ecology block walls did pose some risks. For example, some employees were aware that in the past, walls had been inadvertently contacted by heavy machinery, sometimes leading to wall damage, and occassionally blocks had fallen into material containment areas.

If stacked ecology block walls are used on the worksite for any purpose, all employees that may have exposure to them should receive training to make them aware of risks associated with the walls. Training should also include how to recognize specific hazards, such as leaning or block damage, and how to report hazardous situations when they are found.

The safety program should include a procedure for conducting periodic safety audits of ecology block walls to check for damage or instability.

All employees who may be involved in building ecology block wall structures should receive further training to make them aware of the specific hazards of construction. Training should include how to recognize foundation stability issues, and keeping a safe distance as new blocks are being set into place by equipment operators. Only workers essential to the task should be present during wall construction to minimize worker exposure.

Furthermore, prior to the incident, the company had an active safety program, though without specific information regarding ecology block hazards, which included monthly safety committee meetings involving staff from different departments where workplace hazards were routinely discussed. However, the victim did not usually attend safety 
committee meetings, and had not consulted any other safety committee members prior to beginning the project. The company safety coordinator had not been made aware of the plan to build the wall. Owners and managers should be actively involved in the company safety program, and should lead by example by following all company safety protocols on projects they head.

Safety programs should be updated any time new workplace hazards are recognized.

Recommendation 3: Conduct a thorough job hazard analysis (JHA) before construction begins on any project involving stacked ecology blocks.

Discussion: A job hazard analysis, or JHA, is a process used to identify hazards associated with job tasks, and then develop controls to prevent the hazards. ${ }^{2}$ It considers the relationship between the worker, the task, the tools, and the work environment. By focusing on the steps required to perform a job and considering risk scenarios, potential hazards are recognized and mitigated before workers are put in harms way.

Performing a JHA should include the input of all employees involved in the task. In this case, the victim, being the company owner, made all decisions regarding the safety of the project. The company safety coordinator had not been made aware of the plan to build the wall. If a thorough JHA had been done involving the company safety coordinator and the other employees tasked with building the structure, the seriousness of the risks involving building an ecology block wall on a sand foundation may have been brought into focus. It is important that a JHA be conducted for every appropriate task, including those being directed by business owners or management.

The employer in this case had designed and built numerous ecology block walls in two decades without experience. The U.S. Occupational Safety and Health Administration (OSHA) states that "Jobs with the potential to cause severe or disabling injuries or illness, even if there is no history of previous accidents" should be considered JHA priorities. ${ }^{2}$ While the process that the victim planned to use to build the structure may have been similar to previous situations, the environment (i.e. the loose sand base) was different, and created new risks. A preliminary JHA could have identified and led to a discussion of this new hazard.

Recommendation 4: Encourage employees to recognize and report safety concerns, and train workers on the protocol for reporting hazards. Ensure that all safety concerns are effectively addressed before employees are further exposed to the hazard.

Discussion: After the incident, some of the workers involved reported that they had felt that building ecology block walls on sandy ground was not safe, but were assured by the victim that the structure would be stable when completed. In this situation, the victim's position as owner of the company led the other workers to defer to his judgement, even though their own safety was at stake.

Workers should be encouraged by company leadership to report hazards, and feel that their concerns will be promptly addressed. The other workers on the project may have 
been uncomfortable asserting themselves about safety issues because the victim was the owner of the company. Company leadership should follow all company safety protocols and procedures and, ensure that employees feel comfortable raising safety concerns on projects led by company owners or management.

\section{REFERENCES}

1. Weather Underground. Weather History for KKLS - June 2015 www.wunderground.com/history

2. U.S. Department of Labor Occupational Safety and Health Administration [OSHA]. (2002). Job Hazard Analysis Guide. Publication number: OSHA 3071 https://www.osha.gov/Publications/osha3071.html Accessed August 10, 2016.

\section{ACKNOWLEDGEMENTS}

This report was reviewed by stakeholders from labor and business communities and various Washington State and Federal worker safety agencies. Though we are unable to acknowledge specific individuals for their contributions to this report, we would like to recognize the following for their help and support of the FACE mission and objectives:

- The Employer involved in the incident

- Safety \& Health Assessment \& Research for Prevention (SHARP)

- Division of Occupation Safety and Health (DOSH)

- Federal FACE Program Management (NIOSH)

\section{INVESTIGATOR INFORMATION}

Todd Schoonover has a PhD in Industrial Hygiene from the University of Illinois at Chicago. He is a Certified Industrial Hygienist $(\mathrm{CIH})$ and Certified Safety Professional (CSP). Todd is currently the Principal Investigator for the WA FACE program.

Randy Clark has a BA from The Evergreen State College. He is a Safety and Health Specialist with the WA FACE program.

Christina Rappin has a BA/BS from The Evergreen State College. She is a Research Investigator with the WA FACE program.

\section{WASHINGTON STATE FACE PROGRAM INFORMATION}

The Washington State Fatality Assessment and Control (WA FACE) program is one of many workplace health and safety programs administered by the Washington State Department of Labor \& Industries' Safety \& Health \& Research for Prevention (SHARP) program. Under a cooperative agreement with the National Institute for Occupational Safety and Health (NIOSH grant\# 2U60OH008487-11), WA FACE collects information on occupational fatalities in WA 
State and targets specific types of fatalities for evaluation. WA FACE investigators evaluate information from multiple sources. Findings are summarized in narrative reports that include recommendations for preventing similar events in the future. These recommendations are distributed to employers, workers, and other organizations interested in promoting workplace safety. NIOSH-funded, state-based FACE programs include: California, Kentucky, Massachusetts, Michigan, New York, Oregon, and Washington. WA FACE does not determine fault or legal liability associated with a fatal incident. Names of employers, victims and/or witnesses are not included in written investigative reports or other databases to protect the confidentiality of those who voluntarily participate in the program.

Additional information regarding the WA FACE program can be obtained from:

Washington State FACE Program

www.Ini.wa.gov/safety/research/face/

PO Box 44330

Olympia, WA 98504-4330

1-888-667-4277 


\section{Appendix A}

\section{Ecology Block Wall - Work Permit}

Start Date:

Start Time:

Estimated End Date:

Work Description: (describe the scope of work)

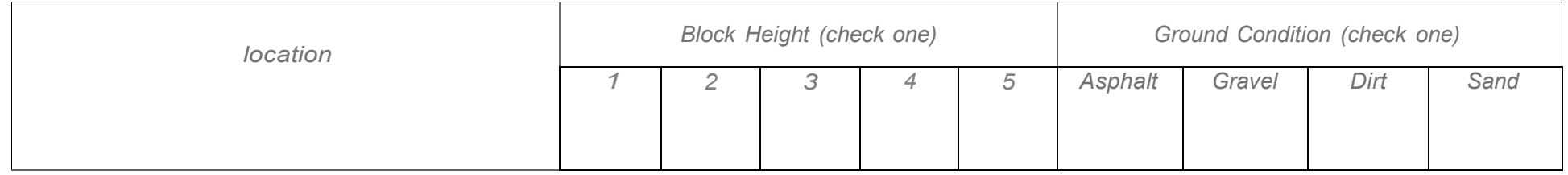

\begin{tabular}{|c|c|c|c|c|}
\hline \multicolumn{2}{|c|}{ Personal Protective Equipment (check all that apply) } & Tools \& Equipment (list below) \\
\hline Hard Hat & & Safety Glasses & & \\
\hline Boots & & $\begin{array}{c}\text { High Visibility } \\
\text { Clothing }\end{array}$ & & \\
\hline Hearing Protection & & Fall Protection & & \\
\hline Dust Masks & & & & \\
\hline
\end{tabular}

Means for restricting unauthorized access: Only allow employees listed on the permit in the work zone.

Hazard Assessment (list all possible hazards associated with this project)

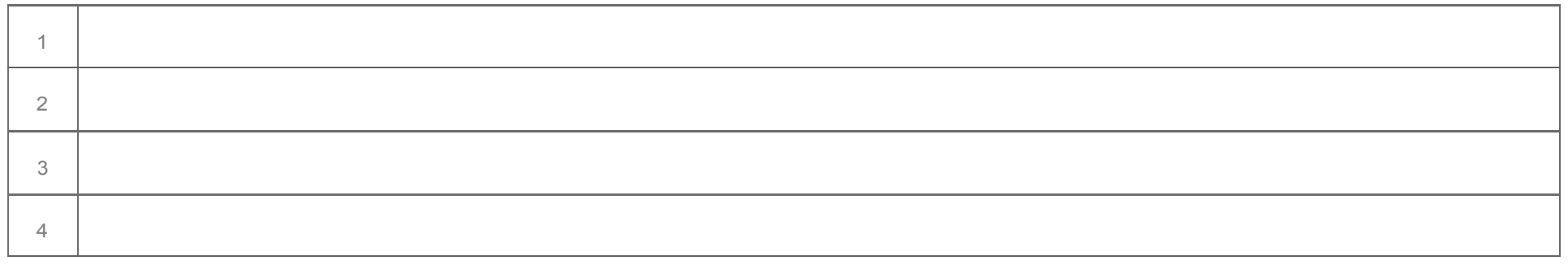

Emergency Response Information: In the event of an emergency call $\underline{911}$. Then notify supervision \& safety coordinator 
Authorized Employees

\begin{tabular}{|l|l|l|}
\hline Employee Name & Date & (Initials) \\
\hline & & \\
\hline & & \\
\hline & & \\
\hline & & \\
\hline
\end{tabular}

\section{Permit approved by the following "Certified" personnel:}

"I have reviewed the proposed EBW work permit and agree that all EBW policies \& procedures have properly been addressed".

$\begin{array}{llll}\text { Name: } & \text { Title:_ Date: } & \text { Initials: } \\ \text { Name: } & \text { Title:_ Date:__n Initials: }\end{array}$

\section{Project inspected by the following "Certified" personnel:}

"I have reviewed the final EBW project and agree that it meets or exceeds safety requirements."

Name:

Name:

Title:

Date

Initials:

Title:

Date:

Initials:

Original Copy - Permit is to be turned into the Safety Coordinator.

Job Site Copy - A copy of the permit is to be kept at job site for the duration of the project.

Return to the safety coordinator when the job is completed.

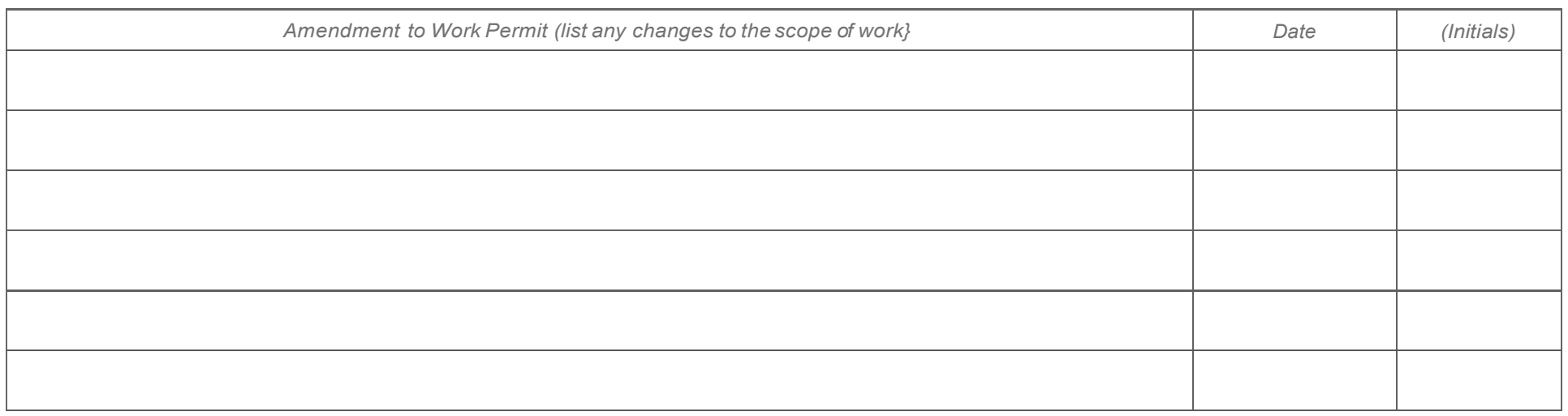

